ISAHP 2005, Honolulu, Hawaii, July 8-10,2005

\title{
Decision making for Raw material Procurement in Paper making factory
}

\author{
Majid Azizi \\ Natural Resources Faculty, \\ University of Tehran \\ mazizi@ut.ac.ir
}

Keywords: AHP, ANP, BOCR, Paper making

Summary: The aim of this article is to determine how to select raw material supply options for paper making factory. The decision-making is examined within the framework of benefits, opportunities, costs, and risks (BOCR). A hierarchy is used to prioritize the BOCR themselves are prioritized using the Analytic Hierarchy Process (AHP) ratings approach. A control hierarchy is then created and prioritized using the Analytic Network Process (ANP) to evaluate the "control criteria" of the system. There are a total of 19 control criteria in the system and each controls a decision network evaluated using the ANP. The final synthesis of the system shows external procurement is the best choice.

\section{Introduction}

At present paper making industry in Iran has very important problem with regard to raw material procurement. In this article, we used AHP (Saaty, 1999) and ANP (Saaty, 2001a) as the tools for selecting the best choice in field of raw material procurement in paper making factory in Iran. There are large demand to paper in the country but Iranian factories cannot produce paper with respect to the demand. The most important problem in paper making industry is inadequate raw material supply and accordingly, amount of product is not satisfied. There are several ways to supply raw material in the factory. External resources, internal resources and mix of them are alternatives to procure raw material in this section.

Because there are various criteria that influence on the decision, in this regard we need powerful method for accurate and inclusive decision making

The paper making factories procure the raw material from forest resources, non forest resources for example poplar tree and agricultural wastes also little amount is procured from foreign countries. There is not logical and scientific methods to decision making in this case. Therefore, almost decisions for procurement of raw material is not proper and products have not high quality so that the marketing of the papers that are produced is not satisfied.

Azizi's research shows procurement of raw material for wood \& paper industries is very important problem because there is serious deficiency in this regard (Azizi, 2003 ).

Background of the studies shows there are several researches which ANP has been applied in it. One example is making decision regarding the establishment of commercial ties with China (Saaty and Cho, 2001b).They concluded Preferred Normal Trade Relations (PNTR) is the best choice.

There is a comprehensive example by Saaty, is about decision on national missile defense program. The US government faces the crucial decision whether or not to commit itself to the deployment of a National Missile Defense (NMD) system. In the research, by applying ANP model, Deploy NMD alternative is the best alternative (Saaty, 2001c). Alikafa E.P., M.S. Ozdemir used ANP and BOCR structure to determine the best policy for EU and Turkey relationship. In this study Membership alternative seems more suggestible according to additive formula (Alikafa and Ozdemir 2003). Iwan J. Azis in his research used ANP to shows the most suitable form of RFA(Regional Financial Arrangement), the process of which involves a complex decision, having to include not just economic rationales but also political and other considerations (Azis, 2003). Poonikom, K. et al applied ANP to propose a systematic framework using ANP for the selection of universities which offer engineering discipline (Poonikom et al., 2003). Y. Ilker Topcu et al studied in food marketing of Turkey, the research developed a multi criteria model of 
organic food marketing strategies which are believed to improve the domestic market. The Analytic Network Process is utilized to construct such a model. The elements of the marketing mix are defined and the interrelationships among these elements are assessed via a Delphi type group decision making procedure ( Ilker et al., 2004). Cevik Sezi, et al to select an Enterprise Resource Planning System applied ANP. Turkey Companies may require an integrated and comprehensive software package that automates flow of materials, information and financial resources among all functions and departments within an enterprise on a common database. The paper presents an integrated framework based on ANP utilizing Delphi Technique ( Cevik et al. 2004). In macro-decision making such as decision making for procurement of raw material for the factories, the best approach is to divide the criteria into favorable and unfavorable. The person making the decision will consider the favorable criteria as benefits and the unfavorable criteria as costs. There are also possible events that may happen as well, which may be considered positive or negative and these are divided into opportunities criteria and risks criteria. Aim of this research is decision making to select to best alternatives with regards to procurement of raw material for paper making factory.

\section{The analytic network process (ANP)}

The ANP is a general theory of ratio scale measurement of influence with a methodology that deals with dependence and feedback. The advantage of this new theory over the AHP (Analytic Hierarchy Process)is its ability to extend to cases of dependence and feedback and generalization of the super-matrix approach. It allows interactions and feedback within clusters (inner dependence) and between clusters (outer dependence).

\section{ANP model}

In this section the ANP model for procurement of paper making raw material is developed. The alternatives are evaluated by the merits of benefits, costs, opportunities, and risks (BOCR).

\subsection{The Alternatives}

There are three potential alternatives for procuring of the paper making raw material. First choice is internal supply of raw material, second is supply from foreign countries or imports and last choice is mixed of them.

\subsection{The merits}

Merits of the research divided to benefits, opportunities, costs, and risks. Benefits is favorable and inevitable criteria, costs is unfavorable and inevitable criteria. Opportunities is possible and positive events and risks is possible and negative events.

\subsection{Overall factors}

In this research the merits of benefits, costs, opportunities, and risks are influenced by following overall factors:

- Social and cultural factors: divided to two factors, literacy \& culture level and population growth.

- Environmental factors related to forest reclamation, wood and non wood agronomy issues.

- Economic factors related to economic issues.

- Governmental laws \& regulations related to imports.

- Foreign trade regulations related to limits of exports from another countries. 


\subsection{Prioritizing BOCR}

Since benefits, opportunities, costs and risks are not equally important, it is necessary to prioritize them. To do that, they are rated with the lowest level of each overall factors and then summing them up. Five possible rating from very high to very low are used. The result of the influence of the overall factors on the merits and the rate of priority of the above mentioned merits are reported in table 1.

Table 1: Priority rating for the merits: Benefits, Costs, Opportunities and Risks very high(1),high(0.51),medium(0.252),low(0.124),very low(0.065)

\begin{tabular}{|c|c|c|c|c|c|}
\hline & Benefits & Costs & Opportunities & Risks \\
\hline \multicolumn{2}{|c|}{ Foreign trade regulations $(0.079)$} & Medium & Very high & Very low & Very high \\
\hline \multicolumn{2}{|c|}{ Governmental regulations( 0.273$)$} & Low & Very high & Medium & Very high \\
\hline \multicolumn{2}{|c|}{$\begin{array}{l}\text { Economic } \\
(0.456)\end{array}$} & Very high & Medium & Very high & High \\
\hline \multirow[t]{2}{*}{$\begin{array}{l}\text { Environmental } \\
(0.154)\end{array}$} & $\begin{array}{l}\text { Forest } \\
\text { reclamation }(0.333)\end{array}$ & Very high & Very low & Very high & Very low \\
\hline & $\begin{array}{l}\text { Wood and non wood } \\
\text { agronomy } \\
(0.667)\end{array}$ & Very high & Low & Very high & Very low \\
\hline \multirow[t]{2}{*}{$\begin{array}{l}\text { Social and } \\
\text { cultural (0.038) }\end{array}$} & $\begin{array}{l}\text { Population growth } \\
(0.25)\end{array}$ & Medium & Medium & Medium & Medium \\
\hline & $\begin{array}{l}\text { Literacy and cultural } \\
\text { level(0.75) }\end{array}$ & Very high & Low & High & Very Low \\
\hline \multicolumn{2}{|l|}{ Overall priorities } & 0.271 & 0.209 & 0.275 & 0.245 \\
\hline
\end{tabular}

Table 1 shows that opportunities and benefits with the priority of 0.275 and 0.271 respectively, have higher priorities than costs and risks in this decision.

\subsection{The Control criteria}

Following the concept of BOCR merits, decisions are most generally approached by breaking them up into merits: benefits, costs, opportunities, and risks. For each merit a sub-network is created with control criteria. When costs and risks are being evaluated, the analysis is done from the perspective of which is more costly or more risky, so that reciprocals of the results are used in synthesizing the results for the final answer.

Four hierarchies for the four merits are introduced. We describe in more details each hierarchy which includes objective (benefits, costs, opportunities, and risks), related sub-criteria.

\subsubsection{Benefits to managers of paper making factories or producers of the paper}

- No harmful on environment

When the raw material is procured for the factory, it is not cause of damages on environment.

- Wood and non wood plantation

Plantation of wood and non wood plants is very helpful in decrease to deforestation with regard to supply of raw material for the factory.

- Decrease of storage cost and increase of selling amount

Supply of suitable and high quality raw material to give rise to produce high quality product, increase in selling amount and decrease in storage cost.

\section{- Create of working}

Due to procuring of proper and adequate raw material in the area of factory establishment, local income and man force absorption improves. The criteria consists two sub-criteria: Increase of local income and absorption of local \&skillful man force. 


\subsubsection{Opportunities to managers of paper making factories or producers of the paper}

- Economic growth of the area

Creation of producing condition and increase in quality procures the condition for economic development in area of factory establishment.

- Export possibilities

Product Export is procured via economic development and high quality products.

- The industry Expansion

By generation of proper condition and procurement of requirement facilities for the factory, expansion of the paper making industry accelerates.

- Investment attraction in future

Potential of the region in terms of the industry expansion which make the investor interested in commissioning the industry in future.

- Access to ISO standards

The managers can get international standards (ISO) for the products via reaching to high quality production.

\subsubsection{Costs to managers of paper making factories or producers of the paper}

- Purchase of raw material

The finished cost for purchasing each cubic meter of forest wood, poplar or orchard wood from their supplying sources to produce the product.

- Raw material transportation cost

Transportation costs from raw material supply areas to the factory site.

- Customs costs

In case of raw material imports, the factory will pay customs costs.

- Deforestation costs

Unwarranted utilization from the forests, give rise to destruction of the forests.

\subsubsection{Risks to managers of paper making factories or producers of the paper}

- Flood possibility

Irregular utilization from the forests and soil erosion generation, procures fair conditions for flood accident

- Decrease of selling amount and increase of storage cost

Improper supply and low quality raw material to give rise to produce low quality product, decrease to selling amount and increase to storage cost.

- Acknowledgment limitation to suppliers of external raw material

The factories which procure essential raw material from foreign countries, whereas, subtend to suppliers restriction, they cannot procure proper and high quality raw material.

- Cutting forbidden issue by government

Due to non-fulfillment, irregular and unwarranted utilization, the government issues non cutting rule which give rise to shut down of the manufacturing process.

- Delay in delivery of external raw material

Whereas the raw material is procure from foreign countries, due to the administrative channels and customs rules, delivery of raw material is operated in delay and if the delivery time takes a long time, it causes to shut down of the manufacturing.

\subsection{Prioritizing Criteria and Alternatives}

After pair wise comparisons between sub criteria for benefits, costs, opportunities and risks, by ANP and pair wise comparisons the criteria and choices against each one of the above mentioned merits are reported in Table 2.

As Table 2 shows, No harmful on environment (0.364), Economic growth of the area (0.346), Purchase of raw material $(0.455)$ and Cutting forbidden $(0.335)$ have the highest priority in terms of 
criteria of benefits, opportunities, costs and risks respectively. Also with regard to alternatives, external supply (0.406), internal supply (0.420), external supply (0.437) and internal supply (0.478) have the highest priority in terms of criteria of benefits, opportunities, costs and risks respectively. To apply the ANP, the Super Decision Software was used. In BOCR structure the following formula is used in calculations (Saaty, 2001d):

$$
\text { (Benefits)*(Opportunities)/(Costs)(Risks) }
$$

\subsection{Networks of Control Criteria}

Figure 1 shows the sub network under benefits which has been obtained by Super Decision Software.

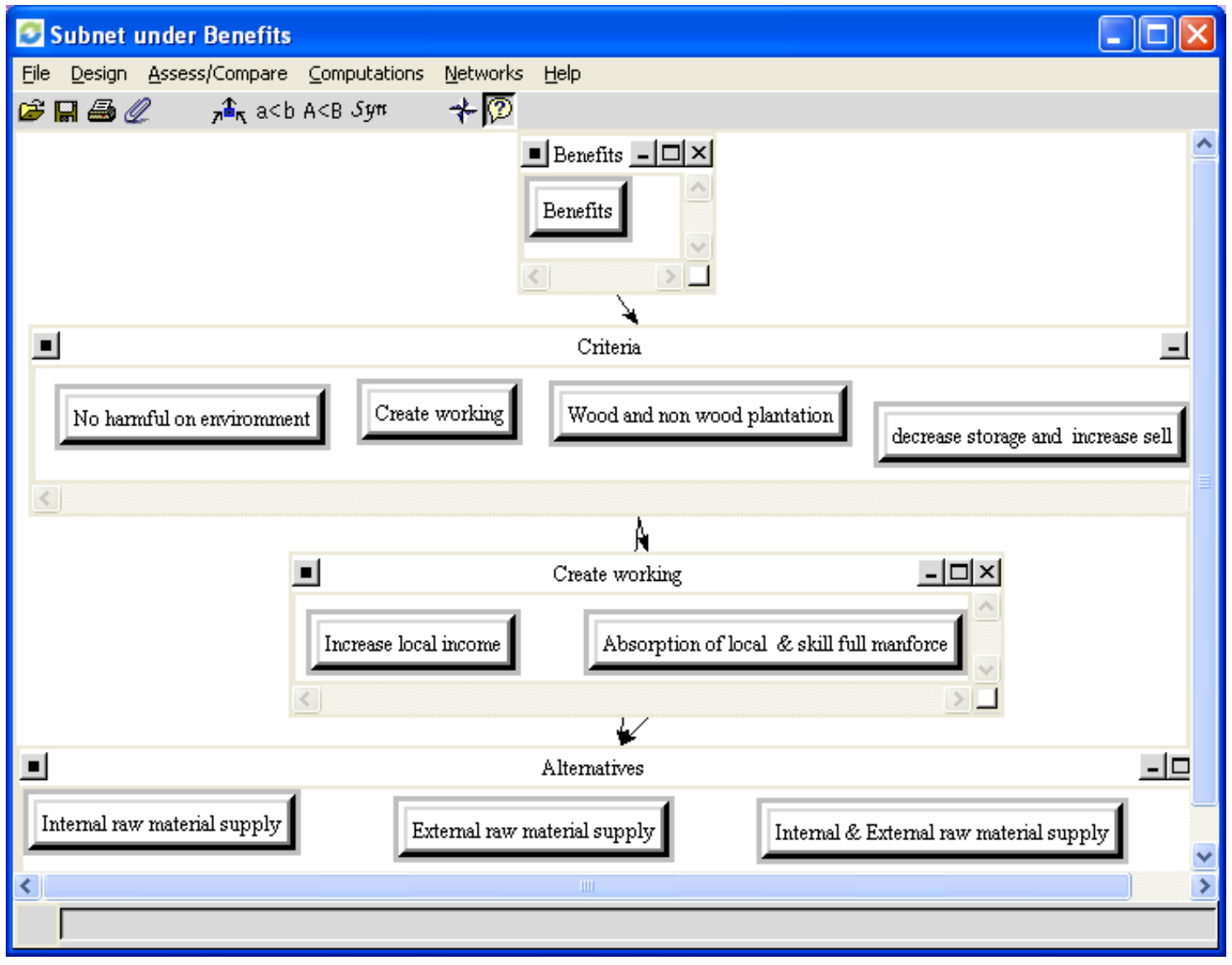

Figure 1: Sub network under benefits

Similarly, the networks for costs, opportunities and risks can be developed. 
Table 2: Synthesized Priorities of the 19 Criteria and Sub criteria

\begin{tabular}{|c|c|c|c|c|c|}
\hline Merits & Criteria & Sub-criteria & $\begin{array}{l}\text { Internal } \\
\text { supply }\end{array}$ & $\begin{array}{l}\text { External } \\
\text { supply }\end{array}$ & $\begin{array}{l}\text { Internal\& } \\
\text { external } \\
\text { s. }\end{array}$ \\
\hline \multirow{5}{*}{$\begin{array}{l}\text { Benefits } \\
(0.271)\end{array}$} & \multirow{2}{*}{ Create of working $(0.13)$} & Increase of local income(0.523) & 0.552 & 0.161 & 0.286 \\
\hline & & $\begin{array}{l}\text { Increase of local \& skillful man } \\
\text { force }(0.477)\end{array}$ & 0.583 & 0.154 & 0.264 \\
\hline & \multicolumn{2}{|c|}{ No harmful on environment(0.364) } & 0.215 & 0.56 & 0.225 \\
\hline & \multicolumn{2}{|c|}{ Wood and non wood plantation(0.203) } & 0.203 & 0.091 & 0.246 \\
\hline & \multicolumn{2}{|c|}{ Decrease of storage \& increase of selling(0.304) } & 0.304 & 0.537 & 0.258 \\
\hline \multicolumn{3}{|c|}{ Benefits Synthesized } & 0.348 & 0.406 & 0.245 \\
\hline \multicolumn{3}{|c|}{ Benefits Normalized } & 0.348 & 0.406 & 0.245 \\
\hline \multirow{5}{*}{$\begin{array}{l}\text { Opportunities } \\
(0.275)\end{array}$} & \multicolumn{2}{|c|}{ Economic growth of the area(0.346) } & 0.654 & 0.086 & 0.26 \\
\hline & \multicolumn{2}{|c|}{ Export possibilities(0.207) } & 0.255 & 0.447 & 0.298 \\
\hline & \multicolumn{2}{|l|}{ Industry development(0.15) } & 0.418 & 0.335 & 0.247 \\
\hline & \multicolumn{2}{|c|}{ Investment attraction in future(0.122) } & 0.363 & 0.358 & 0.28 \\
\hline & \multicolumn{2}{|c|}{ Access to ISO standards(0.175) } & 0.202 & 0.542 & 0.256 \\
\hline \multicolumn{3}{|c|}{ Opportunities Synthesized } & 0.420 & 0.312 & 0.267 \\
\hline \multicolumn{3}{|c|}{ Opportunities Normalized } & 0.420 & 0.312 & 0.267 \\
\hline \multirow[t]{4}{*}{ Costs(0.209) } & \multicolumn{2}{|c|}{ Purchase of raw material(0.455) } & 0.1 & 0.592 & 0.308 \\
\hline & \multicolumn{2}{|c|}{ Raw material transportation cost(0.129) } & 0.09 & 0.661 & 0.249 \\
\hline & \multicolumn{2}{|l|}{ Customs costs $(0.078)$} & 0.082 & 0.687 & 0.232 \\
\hline & \multicolumn{2}{|l|}{ Deforestation costs $(0.338)$} & 0.682 & 0.093 & 0.225 \\
\hline \multicolumn{3}{|c|}{ Costs Synthesized } & 0.296 & 0.437 & 0.266 \\
\hline \multicolumn{3}{|c|}{ Costs Normalized } & 0.296 & 0.437 & 0.266 \\
\hline \multicolumn{3}{|c|}{ Costs Reciprocal } & 0.358 & 0.243 & 0.399 \\
\hline \multirow{5}{*}{$\begin{array}{l}\text { Risks } \\
(0.245)\end{array}$} & \multicolumn{2}{|l|}{ Flood possibility(0.094) } & 0.695 & 0.078 & 0.227 \\
\hline & \multicolumn{2}{|c|}{ Decrease of selling\& increase of storage(0.247) } & 0.604 & 0.126 & 0.27 \\
\hline & \multicolumn{2}{|c|}{ Acknowledgment limits to suppliers(0.127) } & 0.074 & 0.672 & 0.254 \\
\hline & \multicolumn{2}{|c|}{ Cutting forbidden $(0.335)$} & 0.71 & 0.075 & 0.215 \\
\hline & \multicolumn{2}{|c|}{ Delay in deliver of external raw material(0.197) } & 0.075 & 0.66 & 0.265 \\
\hline \multicolumn{3}{|c|}{ Risks Synthesized } & 0.478 & 0.279 & 0.244 \\
\hline \multicolumn{3}{|c|}{ Risks Normalized } & 0.478 & 0.279 & 0.244 \\
\hline Risk Reciprocá & & & 0.214 & 0.367 & 0.419 \\
\hline
\end{tabular}




\subsection{Final Outcome}

By integration of the weights of the merits of benefits, costs, opportunities and risks and the weights of choices against the above mentioned merits, are reported in Table 3.

Table 3: Final Outcome for Priorities of the Alternatives

\begin{tabular}{|l|l|l|l|l|l|}
\hline & $\begin{array}{l}\text { Benefits } \\
(0.271)\end{array}$ & $\begin{array}{l}\text { Opportunities } \\
(0.275)\end{array}$ & $\begin{array}{l}\text { Costs } \\
(0.209)\end{array}$ & $\begin{array}{l}\text { Risks } \\
(0.245)\end{array}$ & $\begin{array}{l}\text { Final } \\
\text { Outcome } \\
\text { Additive }\end{array}$ \\
\hline $\begin{array}{l}\text { Internal } \\
\text { supply }\end{array}$ & 0.348 & 0.42 & 0.358 & 0.214 & 0.336 \\
\hline $\begin{array}{l}\text { External } \\
\text { supply }\end{array}$ & 0.406 & 0.312 & 0.243 & 0.367 & 0.337 \\
\hline $\begin{array}{l}\text { Internal \& } \\
\text { external } \\
\text { supply }\end{array}$ & 0.245 & 0.267 & 0.399 & 0.419 & 0.325 \\
\hline
\end{tabular}

As Table 3 shows the choice of External supply has the highest priority, and is the most suitable choice to procurement of raw material for paper making factory. Considering the merits in decision making, External supply has the highest priority and the second and third are Internal supply and Internal \& external supply (mix of them), respectively.

\section{Conclusion}

As shown in Table 1, opportunities and benefits are more important in the decision compared with costs and risks, because they have higher weight: Opportunities $=0.275$, Benefits $=0.271$.

As Table 2 shows, No harmful on environment (0.364) has the highest priority in terms of benefits. At present one of the most important problems of paper making factory is harmful generation on environment of the area. Irregular utilization from the forests, give rise to destruction of the forests and lack of raw material resources to the factories. Therefore raw material imports is a major programming of the factories. The problem is due to non-fulfillment in performance of plantation and reclamation planning after the utilization. Accordingly conservation of the environment has high priority in this regard. Economic growth of the area (0.346) is the most important criteria in terms of opportunities. Due to proper and high quality production, probably, area of the factory establishment will develop in industrial and business sections and give rise to economic growth of the area. Economic development improves another opportunities sub-criteria. Purchase of raw material (0.455) has the highest priority in terms of costs, because of lack of the proper raw material to produce final product, also raw material supply has been decreased and the demand, extremely, has been increased, due to, using of the many various of wood industries from it. Cutting forbidden (0.335) by the government is very important risk. Area of the forests has been decreased, extremely, due to, irregular and unwarranted utilization, non enough of conservation and reclamation planning by responsible organizations, in past decade, for this reasons, risk of completely cutting forbidden rule will increase in future. As shown in Table 3, external supply with the highest priority is most suitable choice to raw material procurement for the paper making factory. With regard to benefits and costs results as shown in Table 2, external supply choice has the highest priority also internal supply has the highest priority in terms of opportunities, in this regard, this alternative, will generate proper condition for the factory in future, but its result is not inevitable, against, results of inevitable criteria (benefits and costs). As shown in Table 2 with regard to result of risks, using of internal resources has the highest priority and its rate is approximately, twice of other alternatives, but, with respect to Table 1 weight of risks (0.245) is much more than costs (0.209), accordingly, the alternatives with high risks could not be selected or stands in subsequent priorities. Final synthesized shows external resources is the best choice to procure raw material for paper making factory. Although, procurement of raw material from foreign countries has high costs to the factories but in long term 
planning, the interests such as, the high quality products, conservation and no harmful on environment, decrease in deforestation rate are advantages which will occur, follow on, due to, quality increase of the product, access to ISO standards will be easier, the amount of selling will increase and many of the costs, such as storage cost will decrease.

\section{Sensitivity Analysis}

Since there may be different judgments on the comparison of priority rates of benefits, opportunities, costs, and risks or their sub-criteria, to achieve stability and compatibility of the analysis, we apply sensitivity analysis (Saaty, 2001d). About the findings of BOCR hierarchy, by increasing or decreasing one of the criteria, we will find that the ratios of other criteria do not change. For example if the benefit weights increases from 0.346 to 0.5 the sum of other criteria will be equal to 0.5 and the proportion between them will remain consistent and the new weights of other criteria be as follows: Opportunities: 0.271, Costs:0. 094, Risks:0. 135. In this research, about the benefits, whenever the weight of benefits decrease from 0.272 to 0.25 there will be some changes in the establishment of priority for the choices. In such a way that the establishment of priority will be internal supply, internal \& external supply and external supply respectively. The second change, will happen with the decrease in benefits from 0.272 to 0.243 , in such a way that the establishment of priority for internal supply and internal \& external supply will change. Internal \& external supply will be the first priority and internal supply the second priority. If this decrease in benefits continues, this difference will again be greater (Figure 2). If the weight of opportunities increase from 0.275 to 0.285 , then the priorities for external supply and internal supply will change. Internal supply will be the first priority and external supply the second. The more the increase, the more this difference. If the weights of opportunities decrease from 0.275 to 0.257 , in such a way, that the establishment of priority will change. Internal \& external supply will be the second priority, internal supply the third. If the decrease in opportunities continue down to 0.164 , then internal \& external supply will be the first priority, external supply the second. If this decrease continues, difference between external supply and internal supply will be greater (Figure 3). About the costs, whenever the weight of costs increase from 0.209 to 0.218 , there will be change in the establishment of priorities for the choices. In such a way that at this point internal supply is the first, internal \& external supply will be the second and external supply the third. If the increase in costs continues up to 0.271 , then internal \& external supply will be the first priority, internal supply the second. The more the increase, the more this difference (Figure 4 ). If the weight of risks increase from 0.244 to 0.26 , then the priorities for internal \& external supply and internal supply will change. Internal \& external supply will be the second priority and internal supply the third. If the increase in risks continues up to 0.31 , then internal \& external supply will be the first priority, external supply the second. The more the increase, the more this difference (Figure 5 ). Also, if the weight of risks decrease from 0.244 to 0.239 , then the priority for external supply and internal supply will change. Internal supply will be the first priority and external supply the second. The more the decrease, the more this difference (Figure 5). 


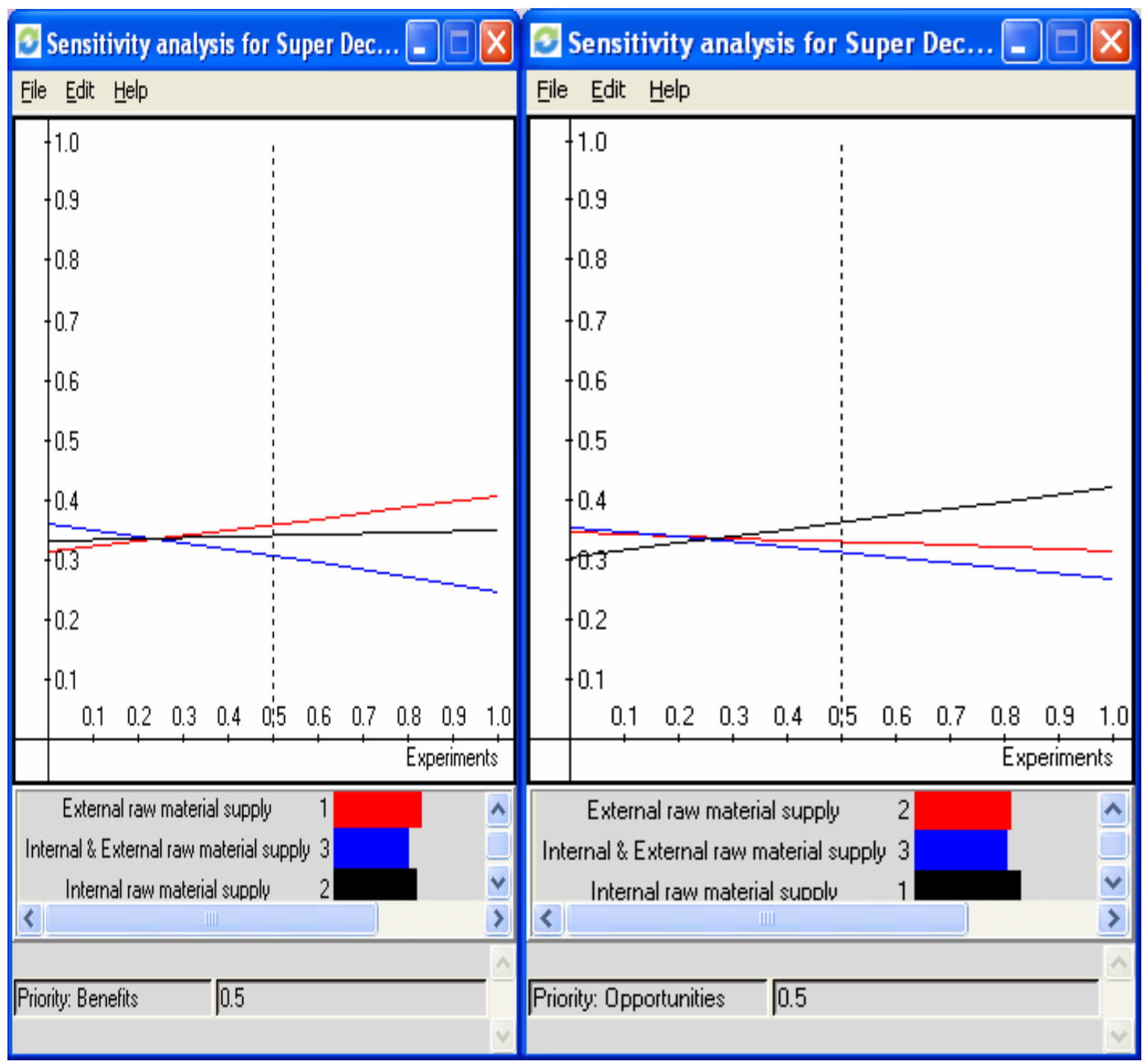

Figure2: Sensitivity analysis for benefits

Figure 3: Sensitivity analysis for opportunities 


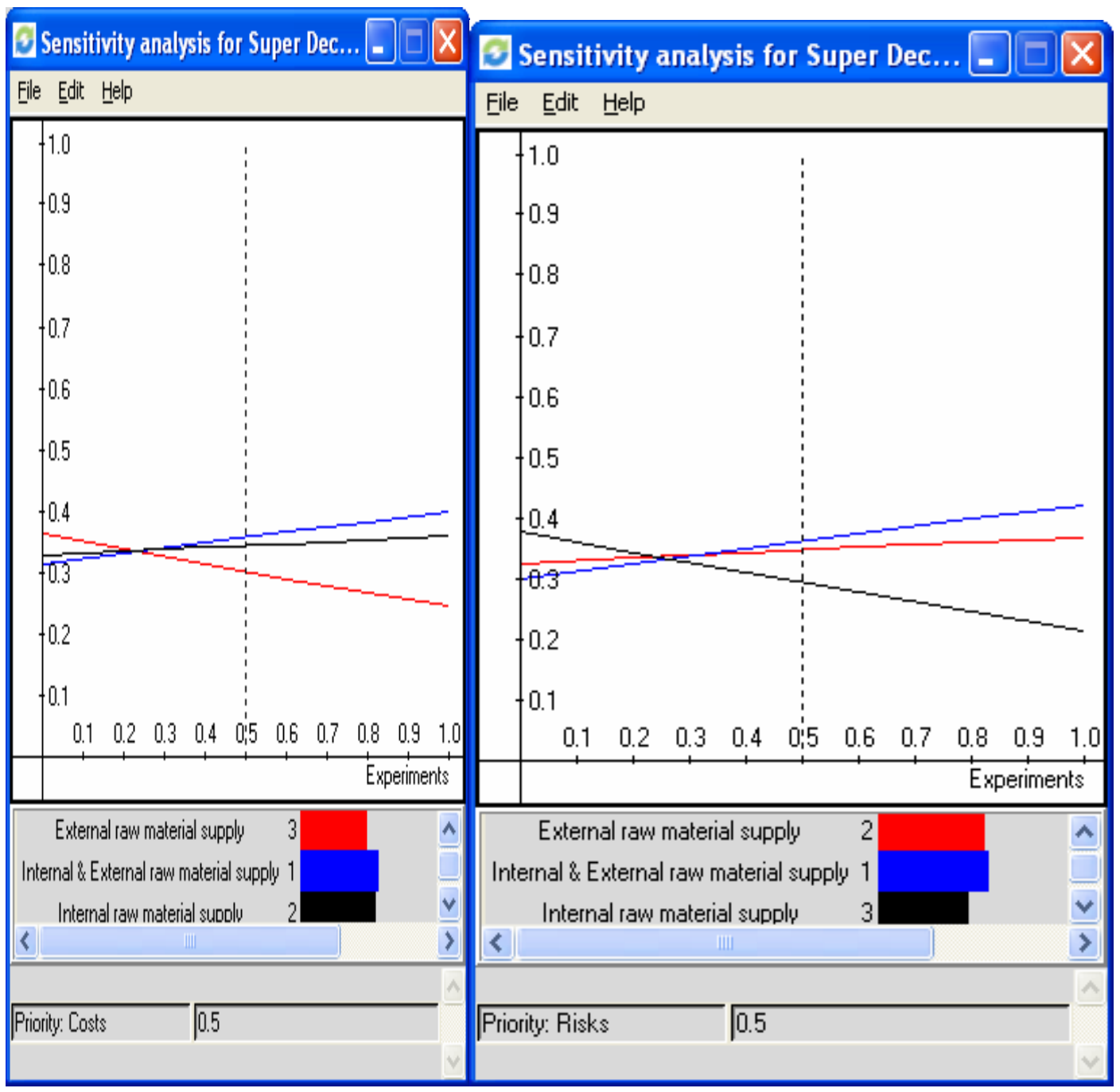

Figure 4: Sensitivity analysis for costs Figure 5: Sensitivity analysis for risks

\section{References}

Saaty T., (1999) Decision Making for Leaders, RWS Publications, 4922 Ellsworth Avenue, Pittsburgh, PA 15213.

Saaty T., (2001a) Decision Making with Dependence and Feedback:The Analytic Network Process, RWS Publications, Pittsburgh, PA.

Azizi M. , Modarres M., Amiri S., Faezipour M., Doosthoseini K., (2003) "The group decision making to determine effective criteria for wood industry location (Case of study: Iran)” , International Journal of Inquiry, Vol. 1, No. 1, 63-96 
Saaty T. and Y. Cho, (2001b), “The Decision by the US Congress on China's Trade Status: a Multicriteria analysis”, Socio-Economic Planning Sciences, 35, 243-252, Elsevier ScienceLtd.

Saaty T., (2001c) "Decision on National Missile Deffense Program", The $6^{\text {th }}$ International Symposium on the AHP in Bern, Switzerland.

Alikafa E.P., M.S. Ozdemir, (2003) "The best policy for European Union \& Turkey Relationship”, Proceeding of the Seventh International Symposium on the Analytic Hierarchy Process , ISAHP2003, Bali, Indonesia, p: 97-110.

Azis Iwan J., (2003) "Complex Decision in the establishment of Asian Regional Financial Arrangement", Proceeding of the Seventh International Symposium on the Analytic Hierarchy Process , ISAHP2003, Bali, Indonesia, p: 39-56.

Poonikom, K., Chansa- ngavej, C., O’Brien, C., (2003) "A Framework for Universities - Selection Decision using the Analytic Network Process (ANP) ", Proceeding of the Seventh International Symposium on the Analytic Hierarchy Process, ISAHP2003, Bali, Indonesia, p:403-416.

Ilker Y. Topcu, Sebnem Burnaz, and Suha Urgan, (2004) "Modeling marketing strategies in organic food through analytic network process”, MCDM 2004 conference, Whistler, B. C. Canada August 611 .

Cevik Sezi, Aktas Emel and Topcu Y. Ilker, (2004) "Selection of an Enterprise Resource Planning System using Analytic Network Process: The case of Turkey”, 20 th European Conference on Operation Research, OR and the Management of Electronic Services, July 4-7, Rhodes, Greece, Abstract book, p:87.

Saaty T., (2001d) Decision Making in Complex Environments, The Analytic Network Process for Decision Making with Dependence and Feedback, University of Pittsburgh. 